\title{
Empirical Analysis on Influencing Factors of Online Job Seeking
}

\author{
Xinwen Cao \\ Business School \\ Sichuan Agricultural University \\ Chengdu, China
}

\author{
$\mathrm{Fu} \mathrm{He}$ \\ Business School \\ Sichuan Agricultural University \\ Chengdu, China
}

\author{
Wanqing Ma \\ Business School \\ Sichuan Agricultural University \\ Chengdu, China
}

\begin{abstract}
The objective is to study the influence of online information on online job search, in particular, the influence of the number of times the job was viewed and the resume feedback rate of the job on the number of online applications for the job. [Methods] Based on the data of 8292 Shanghai cities and 3414 Chengdu areas of 58 cities in the same city, the author studied the influence of the number of visits and establishment of feedback rate on the number of online applications for this position by using multiple linear regression model combined with expectation theory. [Conclusion] Except basic salary, welfare and other content, the number of online job postings and the resume feedback rate of the position will also have a significant impact on the number of online applications for the position. Visible company hiring should also try to show such information to attract job seekers.
\end{abstract}

Keywords-the number of online applications; online browsing; resume feedback rate; multiple linear regression; expectations theory

\section{INTRODUCTION}

With the continuous development of the Internet era, online recruitment has become an indispensable part of the life of job seekers. Online recruitment is also referred to as online recruitment or e-recruitment. It refers to the recruitment activities carried out through Internet technologies, including the release of various recruitment information, the collection and sorting of resumes, online evaluation and evaluation, and e-interview [1]. At this stage, the market size of online recruitment has experienced steady growth after experiencing the four phases of exploration, market start-up, rapid development and maturity, and the market share of online recruitment has also shown a steady growth. According to the "China Internet Recruitment Market Annual Report 2016" released by Analysys, the online market for China's online recruitment has reached 4.35 billion yuan in 2015. It is predicted that although the growth rate will decline in the next three years, it will still be maintained relatively steady growth [2].
Online recruiting breaks the time and geographical constraints of traditional hiring, finding suitable talents for business users while also providing job seekers with a way to find more suitable units [3]. Online recruitment also has the advantages of low recruitment cost, quick and efficient recruitment process, strong recruitment hiring, large two-way information volume and fast update speed [4]. With the rapid development of the Internet, the advantages of all parties become more prominent [5]. However, due to the rapid development of the times, the continuous expansion of the information volume, the continuous increase of job-seekers' working pressure and the continuous increase of influencing factors, it is difficult to direct symmetry between the recruitment demand and the recruitment information in various fields. Therefore, Information more effectively extracted from the information that can be used as employers and job seekers together need to face the problem. There are many factors that can influence online recruitment decisionmaking in the process of online recruitment. The factors that play a role in the decision-making process are very worth exploring in depth; determining the proportion of different influencing factors and making better decisions for online recruitment improve the recruitment program.

The hierarchy of online recruitment talents is obviously divided, and the hierarchy needs to be continuously improved. The security, timeliness and authenticity need to be continuously improved under the condition of high security. The development of online recruitment still requires clever combination with other recruitment methods in order to seek better development [6]. Establishing a good credit system is also an important issue that needs to be paid attention to on the major online recruitment websites. Whether it is a recruitment unit, an online website or an individual seeking employment, it needs a good credit, real and direct information to achieve the efficiency of online recruitment, taking advantage of online recruiting. 


\section{LITERATURE REVIEW}

\section{A. Related Research Review}

Some scholars have conducted a detailed survey on the status quo and trends of online recruitment usage. Relevant results show that most college students are willing to use online recruitment for job search. Therefore, the trend of online recruitment is still considerable, need to continuously improve the recruitment decision-making process, and solve the problems encountered in the online recruitment process, to better prepare for the network recruitment talent service to make adequate preparations.

Some scholars have carried out relevant research on online recruitment, such as Tina Christensen [7] to compare the efficiency and cost of online and offline recruitment methods, Barry Smyth [8] and other research to provide users with personalized information Search to better improve online recruitment services, Joanna P.C.Tong [9] to assess the quality of online service recruitment website quality and service quality and psychological load and performance time, Taylor S Lane [10] found that a variety of online recruitment methods Purpose and Results, E Parry [11] uses a large scale vertical survey recruitment activity Investigate employer and corporate website usage and perceived success and gain insight into factors that may affect the success of these methods. Chen Haitao [12] and other empirical analysis of the online recruitment based on the social recruitment of users information sharing factors, Chen Ming tear [13] for the status quo and advantages of online recruitment corresponding strategies for improvement. Although there are increasing problems and research on online recruitment, the research on the factors influencing the recruitment efficiency of online recruitment is still incomplete. Therefore, it is necessary to carry out a large amount of empirical research and verification on related factors.

\section{B. Expectation Theory}

The study of expectation theory originated in the 1960s, proposed by the famous psychologist and behavioral scientist Victor Vroom, which provided a comprehensive theoretical framework for personal motivation. Expectations theory believes that the premise of stimulating an individual to carry out a specific behavior is to make them aware of the possible consequences of this behavior to meet their own needs. The strength of the motivation depends on how well individuals align with and agrees on the work performance (organizational goals) that the organization is trying to achieve, the rewards (personal goals) that are rewarded based on the work performance organization, and the personal needs it achieves. Consistency or relevance, the effect is large, otherwise small [14]. The expected value, also known as the expected probability, is influenced by the individual's experience, personality, emotion, motivation. Present expectation theory is often applied to research and performance management, staff motivation and other aspects, in the process of online recruitment also need to estimate the expectations of each link theory, the expected value and the potency into online recruitment system assessment.
Tang Pingqiu [15] and other expectations theory as the framework of the college think tank motivation elements and environment research, Huang Ling [16] based on the expected theory of successful crowd funding project design issues, extending to the financial behavior of the theory of expectations, Liu Yongan [17] applied the expectation theory to the management level and put forward a lot of constructive suggestions for the enterprise management. Thus, in the process of online recruitment management can be expected to use theory as a theoretical basis for the determination and adjustment of influencing factors. Based on the study of the influencing factors of online job hunting, this paper finds that the change of some factors will stimulate the enthusiasm of online job hunting. Therefore, using expectation theory can well study the influence of online information on job searching.

\section{EMPIRICAL ANALYSIS}

\section{A. Propose a Hypothesis}

1) Views: At present, the online recruitment market in China is fiercely competitive with a high degree of homogeneity [18]. Most of the online recruitment websites only contain some basic information such as salary, academic qualifications and experience requirements, but the basic information does not reflect the online acceptance of the job Welcome, but also cannot provide good guidance for later users. Based on this, some of the system-generated information such as: the number of online views and the number of online applications can be a good solution to this problem, it should also be analyzed. System-generated information refers to the data generated by the actions of users or consumers [19]. Currently, these data play a very important role in the Internet field, especially in the further transformation of consumer behavior in network marketing. At present, the information is widely used in online digital music marketing [20], sales of website books [21][22] and movie recommendation [23]. Because the network recruitment cannot reflect the actual situation of the work, so this part of the information on the user online job has a more important value.

The number of online views refers to the number of online views of the work, to a certain extent, reflects the online popularity of the work. The number of online applications refers to the job of submitting a resume online after browsing the work. Research has shown that there is a close relationship between eWOM and online browsing [24]. Since this part of the information is generated by user behavior, it has a more significant impact on the user's online decision-making later than other information with high confidence, number of online views and online application, and therefore makes the following assumptions:

H1: The number of online views can have a significant positive impact on the user's online job search.

2) Resume feedback rate: Resume feedback rate refers to the probability that a user submits a resume for a resume 
after the user submits the resume online. The resume feedback rate $=$ the number of resumes sent $/$ the number of resumes received. Resume feedback rate can represent the business response to user applications probability. Online feedback is the "word of mouth" digitization and networking [25]. At present, the online feedback mechanism is widely used in the study of e-commerce [26], after-sales service [27] and credit rating [28] In the play an important role. Therefore, the online resume of the company on the future number of users to apply for the post also have a certain degree of impact, made the assumption:

$\mathrm{H} 2$ : Higher resume feedback rate has a significant positive impact on users' online job search.

\section{B. Data and Variable Descriptions}

The data of this experiment all sources and 58 cities under the job site recruitment information above, 58 city located in the local community and free classified information service, its subordinate recruitment website can provide more comprehensive job information, the information not only includes the position Address, the required academic experience and wages and other basic information, but also provide the position of the number of visits, the number of applicants and other information, so we choose 58 city data collection. This data is collected based on a Python crawler data. Due to the current grading of cities in China, the first-tier cities such as Beijing, Shanghai and Guangzhou are developing rapidly with relatively more jobs. Meanwhile, emerging first-tier cities such as Chengdu and Wuhan are also developing rapidly. Therefore, we chose Shanghai and Chengdu, two cities for data collection. After data cleaning, collected a total of 8292 Shanghai area data and 3414 data in Chengdu. Because part of the data is more discrete, and in order to avoid the multicollinearity between the data, part of the data is taken into the model to calculate the logarithm, the data characteristics are as follows:

TABLE I. DATA CHARACTERISTICS

\begin{tabular}{|l|l|l|l|l|l|l|}
\hline \multicolumn{1}{|c|}{ variable } & \multicolumn{1}{|c|}{ Obs } & average value & $\begin{array}{c}\text { Standard } \\
\text { deviation }\end{array}$ & Minimum & Maximum & VIF \\
\hline Ln(apply) & 9,805 & 2.73 & 1.77 & 0 & 8.24 & ---- \\
\hline Ln(browse) & 11,597 & 5.79 & 2.10 & 0 & 12.56 & 1.16 \\
\hline Ln(salary) & 11,708 & 8.73 & 0.44 & 7.31 & 10.92 & 1.02 \\
\hline Ln(recruit) & 11,706 & 2.16 & 1.27 & 0 & 6.91 & 1.27 \\
\hline Ln(scale) & 11,708 & 5.66 & 1.18 & 3.91 & 6.91 & 1.06 \\
\hline Resume & 11,708 & 0.62 & 0.39 & 0 & 1 & 1.05 \\
\hline Welfare & 11,708 & 3.40 & 1.09 & 0 & 4 & 1.05 \\
\hline Experience & 11,708 & 1.48 & 0.95 & 1 & 7 & 1.21 \\
\hline
\end{tabular}

TABLE II. CORRELATION TEST OF VARIABLES

\begin{tabular}{|l|l|l|l|l|l|l|l|c|}
\hline \multicolumn{1}{|c|}{ variable } & \multicolumn{1}{|c|}{ Apply } & Resume & Browse & Salary & Welfare & Recruit & Experience & Scale \\
\hline Apply & 1.000 & & & & & & & \\
\hline Resume & $-0.028^{*}$ & 1.000 & & & & & & \\
\hline Browse & $0.919^{*}$ & $-0.026^{*}$ & 1.000 & & & & & \\
\hline Salary & -0.019 & 0.001 & 0.004 & 1.000 & & & & \\
\hline Welfare & $0.039^{*}$ & $0.107^{*}$ & 0.014 & -0.003 & 1.000 & & & \\
\hline Recruit & 0.017 & $0.108^{*}$ & 0.009 & $0.124^{*}$ & $0.076^{*}$ & 1.000 & & \\
\hline Experience & 0.000 & $-0.097^{*}$ & $0.053^{*}$ & $-0.018^{*}$ & -0.009 & $-0.351^{*}$ & 1.000 & \\
\hline Scale & $0.058^{*}$ & $0.065^{*}$ & $0.083^{*}$ & $0.022^{*}$ & $0.081^{*}$ & $0.043^{*}$ & $-0.99^{*}$ & 1.000 \\
\hline
\end{tabular}

TABLE III. DESCRIPTION OF VARIABLES

\begin{tabular}{|l|l|l|}
\hline Variable category & \multicolumn{1}{|c|}{ Variable name } & \multicolumn{1}{c|}{ Variable Description } \\
\hline Dependent variable & The number of applications & $\begin{array}{l}\text { Indicates the number of online applications } \\
\text { since you viewed this post }\end{array}$ \\
\hline Argument & Resume feedback rate & $\begin{array}{l}\text { Indicates the probability of feedback after } \\
\text { the company received the resume }\end{array}$ \\
\hline Control variables & Views & She number of visits to the position \\
\hline & welfare & $\begin{array}{l}\text { After the post salary } \\
\text { The amount of benefits included in this } \\
\text { position }\end{array}$ \\
\hline & Number of recruits & The number of job recruitment number \\
\hline & work experience & The position required job experience \\
\hline & Enterprise size & The number of employees in the enterprise \\
\hline
\end{tabular}

\section{Model Estimation}

Users are often affected by several factors when applying for the position online, so use multiple linear regression models to test online views and establish the impact of applying for the position online. In this experiment, we will use the number of online applications as dependent variables, the number of online browsing and resume. The rate of return as an independent variable, the salary level, job benefits, the number of recruits and work experience and business size as a control variable into the model for analysis. 
To avoid multicollinearity, log the partial fields into the model as shown below:

$$
\ln (\text { apply })=\beta 0+\beta 1 \ln (\text { browse })+\beta 2 \ln (\text { salary })+\beta 3
$$

$\ln ($ recruit $)+\beta 4 \ln ($ scale $)+\beta 5$ resume

\section{$+\beta 6$ welfare $+\beta 7$ expeirence}

Apply represents the number of online applicants for the position, to some extent reflects the degree of conversion of the job after being viewed; Browse represents the number of online views of the job, which reflects the online popularity of the job; Salary said Of the salary level; recruit said the number of positions expected to recruit, to some extent, the position of the competition can be seen the intensity of the scale; scale that the position of the company released the company, the main measure is the company's existing staff, the largest Is above 1000, and at least below 50; Resume refers to the resume feedback rate is the probability of feedback after the company received a resume; Welfare said the number of benefits provided by the position, including five insurance and a weekend and weekends, etc. , A maximum of 4 benefits, and a minimum of 0 benefits; Experience represents the work experience required by the job owner

Seeking, at least is an acceptable to fresh student do not need work experience, up to 10 years.

\section{RESULTS}

Due to the possible inter-variable correlation among the regression models, this paper uses stepwise regression in regression analysis to test the possible multicollinearity of the model. It is after Stata statistical software analysis. Regression model through the online browsing and resume feedback rate calculation, the final correction coefficient and $\mathrm{t}$ test are to meet the requirements, the specific results as shown below:

TABLE IV. EMPIRICAL RESULTS

\begin{tabular}{|l|l|l|}
\hline & \multicolumn{1}{|c|}{ Model 1 } & \multicolumn{1}{c|}{ Model 2 } \\
\hline Constant term & $\begin{array}{l}2.773^{* * *} \\
(7.44)\end{array}$ & $\begin{array}{l}2.005^{* * *} \\
(13.97)\end{array}$ \\
\hline Salary & $-0.093^{* *}$ & $-0.081^{* * *}$ \\
& $(-2.23)$ & $(-5.11)$ \\
\hline Recruit & $0.026^{*}$ & $0.140^{* * *}$ \\
& $(1.66)$ & $(23.32)$ \\
\hline Scale & $0.086^{* * *}$ & $0.023^{* * *}$ \\
& $(5.53)$ & $(3.82)$ \\
\hline Welfare & $0.054^{* * *}$ & $0.056^{* * *}$ \\
& $(3.28)$ & $(8.80)$ \\
\hline Experience & 0.023 & $-0.037 * * *$ \\
& $(1.19)$ & $(-4.92)$ \\
\hline Browse & & $0.914 * * *$ \\
& & $(239.89)$ \\
\hline Resume & & $0.054 * * *$ \\
& & $(2.98)$ \\
\hline Adjust-R & 0.402 & 0.855 \\
\hline F & 400.96 & 8285.63 \\
\hline $\mathrm{N}$ & 9803 & 9802 \\
\hline
\end{tabular}

b. *** indicates a significant level of $1 \%$, ** indicates a significant level of 5\%, * indicates a significant level of $10 \%$
As can be seen from the table above, the regression coefficients of Browse $(\mathrm{B}=0.914, \mathrm{~T}=239.89, \mathrm{P}<0.01)$ for online browsing are significant. Suppose H1 is verified that online browsing will have a significant positive impact on users' online job search; at the same time, Resume rate $(\mathrm{B}=$ $0.054, \mathrm{~T}=2.98, \mathrm{P}<0.01)$. The regression coefficient is significant. Suppose H 2 is verified that higher resume feedback rate has a significant positive impact on users' online job search. Both of these assumptions are validated, meaning that the number of online views and resume response rates does actually cause users to see jobs significant impact. In addition, it can also be seen from the above table that the number of posts, the size of the enterprise and the post welfare also have a significant impact on users' online job search.

\section{CONCLUSION}

This article is based on the existing online recruitment articles, starting from the job site information displayed on the job site, focusing on online browsing and resume rate on the impact of online job search, online recruitment to make the appropriate guidance. At the same time, this paper also takes full account of the factors such as salary, welfare and enterprise size, and establishes a multiple linear regression model to verify the hypothesis. Finally found that online views and resume rate of return will indeed have a significant impact on the user job search, which also shows that online job-seekers are more willing to deliver those with more views, resumes a larger rate of return of work, so businesses in the network In addition to providing better conditions for recruitment, but also to say such information on the prominently placed to attract job seekers to deliver resumes.

\section{REFERENCES}

[1] Yu Hongyi. Network recruitment status and Countermeasures Analysis [J]. Economic research reference, 2014 (29): 92-95.

[2] Liu Zhe. Analysis of the current situation and development trend of enterprise network recruitment [J]. Chinese business theory, 2017 (1): 78-79.

[3] Tang Lijun. Research on the influencing factors of effective implementation of Internet recruitment [J]. Regional economic review, 2010 (4): 72-74.

[4] Li Li, Zhang Xinyi. An Empirical Study on the implementation of network recruitment for small and medium-sized enterprises [J].Enterprise economy, 2010 (2): 25-28.

[5] Tian Zhaofu. The status of Internet recruitment and problems to be paid attention to [J]. Business research, 2004 (9): 174-175.

[6] Christensen T, Riis A H, Hatch E E, et al. Costs and Efficiency of Online and Offline Recruitment Methods: A Web-Based Cohort Study:[J]. Journal of Medical Internet Research, 2017, 19(3):e58.

[7] Smyth B, Bradley K, Rafter R. PERSONALIZATION TECHNIQUES FOR ONLINE RECRUITMENT SERVICES[J]. Communications of the Acm, 2002, 45(5):39-40.

[8] Tong J P C, Duffy V G, Cross G W, et al. Evaluating the industrial ergonomics of service quality for online recruitment websites[J]. International Journal of Industrial Ergonomics, 2005, 35(8):697-711.

[9] Lane T S, Armin J, Gordon J S. Online Recruitment Methods for Web-Based and Mobile Health Studies: A Review of the Literature[J]. Journal of Medical Internet Research, 2015, 17(7):e183. 
[10] Parry E, Tyson S. An analysis of the use and success of online recruitment methods in the UK[J]. Human Resource Management Journal, 2008, 18(3):257-274.

[11] Chen Haitao, Chen Hao, Dong Zhaohui, et al. Research on the influencing factors of social recruitment users' information sharing, [J]. Information science, 2017 (8): 153-158.

[12] Chen Mingsi. New channel business recruitment network recruitment [J]. Rural economy and science and technology, 2016, 27 (14): 142143.

[13] Li Baoyuan. Strategic motivation of modern enterprise human resources management of motivation: Essentials $=$ Strategic of human resource managemnt in modern enterpri[M]. Economic Science Press, 2005.

[14] Zhao Xiangyu, Zhang Jie. Research on incentive management of young college teachers from the perspective of expectation theory $[\mathrm{J}]$. Education review, 2017 (10): 125-128.

[15] Liu Yongan. The application of the expectation theory to the management of [J]. Enterprise economy, 2002 (6): 73-74.

[16] Tang Pingqiu, Jiang Xiaofei. Researchers in college think tank based on expectation theory inspire: Plight and Countermeasures [J]. Chinese administration, 2017 (1).

[17] Huang Ling, Zhou Qin. Research on public design based on expectation theory [J]. Financial science, 2015 (6): 32-42.

[18] Zhao Qingbin, Ji Hanlin, Liu Dongbo. China's Internet recruitment industry: development status, trend and strategy $[\mathrm{J}]$. Business research, 2012 (9): 43-49.

[19] Westerman D, Spence P R, Heide B V D. A social network as information: The effect of system generated reports of connectedness on credibility on Twitter[J]. Computers in Human Behavior, 2012, 28(1):199-206.

[20] Dewan S, Ramaprasad J. Research Note---Music Blogging, Online Sampling, and the Long Tail[J]. Information Systems Research, 2012, 23(3-Part-2):1056-1067.

[21] Chen $\mathrm{P}$ Y S, Wu S Y, Yoon J. The Impact of Online Recommendations and Consumer Feedback on Sales[C]// International Conference on Information Systems, Icis 2004, December 12-15, 2004, Washington, Dc, Usa. DBLP, 2004:711-724.

[22] Chevalier J A, Mayzlin D. The Effect of Word of Mouth on Sales: Online Book Reviews.[J]. Social Science Electronic Publishing, 2006, 43(3):345-354.

[23] Amolochitis E, Christou I T, Tan Z H. Implementing a CommercialStrength Parallel Hybrid Movie Recommendation Engine[J]. IEEE Intelligent Systems, 2014, 29(2):92-96.

[24] Pang Lu, Li Junyi. Electronic word-of-mouth on online restaurant views on [J]. Travel journal, 2014, 29 (1): 111-118.

[25] Li Hongmei. Analysis of online feedback mechanism [J]. Modern information, 2011, 31 (6): 29-32.

[26] Ji Shhuxian. Research on the effectiveness of online reputation feedback system in C2C E-commerce [D]. Southwest Jiaotong University, 2009.

[27] Liu Zilong. Based on the feedback mechanism of online consumer after service guarantee system design [J]. Consumer economy, 2007, 23 (5): 80-83.

[28] Kuwabara K. Reputation Systems: Facilitating Trust in Internet Interactions[J]. Communications of the Acm, 2000, 43(12):45-48. 